Price dynamics of cryptocurrencies in parallel markets: evidence from Bitcoin exchanges in Brazil

\begin{tabular}{|r|l|}
\hline Journal: & Studies in Economics and Finance \\
\hline Manuscript ID & SEF-11-2020-0450.R2 \\
\hline Manuscript Type: & Research Paper \\
\hline Keywords: & Bitcoin, Law of One Price, Price Discovery, Cryptocurrencies \\
\hline \multicolumn{2}{|l}{} \\
\end{tabular}




\title{
Price dynamics of cryptocurrencies in parallel markets: evidence from Bitcoin exchanges in Brazil ${ }^{*}$
}

\author{
April 9, 2021
}

\begin{abstract}
Purpose We study the dynamics of bitcoin prices in Brazil, a large emerging economy with an unregulated bitcoin market.

Design/methodology/approach First, we test if the Law of One Price (LOOP) is valid for bitcoin prices in Brazil, conducting tests with data from three Brazilian exchanges. Next, we document bitcoin price dynamics in the short run by studying the price discovery mechanism in these exchanges. We use Information Share and Component Share, combining the two measures to obtain an Information Leadership Share (ILS) measure.

Findings We find a common trend within bitcoin prices among a set of exchanges, with cointegration tests between the price series indicating that LOOP is valid in Brazilian markets in the long run. ILS indicated that, for closing prices, the most liquid exchange (Foxbit) leads discovery, while the least liquid (Local Bitcoin) lags, with Mercado Bitcoin in the middle both in terms of discovery and liquidity. Finally, we provide evidence that the price variation in the market that leads price discovery can be used to construct an arbitrage in another exchange.

Originality Our research brings the first evidence of a price discovery mechanism for exchanges in Brazilian Reais. Although LOOP is valid in the long run, price leadership in bitcoin markets potentially create arbitrage opportunities in the short run. We contribute to the growing literature of bitcoin prices with novel evidence from a large emerging economy.

Keywords: Bitcoin; Law of one Price; Price Discovery; Cryptocurrencies.
\end{abstract}

\footnotetext{
*Previous circulated as Bitcoin in Brazil: Law of One Price and Price Discovery in an Emerging Market.
} 


\section{Introduction}

Digital currency was a technology put in practice in the 1990s in the form of stored value cards for peer-to-peer (P2P) payments that did not require bank authorization. Bitcoin is an online communication protocol based on cryptography and information technology to facilitate P2P transactions. Despite some similarities with traditional digital payment methods (e.g. medium of exchange and store of value), two characteristics make it distinct: transactions can be made anonymously and decentralized (Nguyen et al., 2018). Kristoufek (2015) has pointed out some bitcoin advantages, such as low or no fees, a controlled and known algorithm for currency creation, and informational transparency for all transactions. On the other hand, bitcoin suffers from some shortfalls such as the scalability problem and high energy consumption from mining (Karame, 2016, Poon and Dryja, 2016, Narayanan et al., 2016). ${ }^{1}$ However, the factor that attracts more attention both to media and investors is bitcoin price (Nguyen et al., 2018). The first study to address bitcoin price formation was conducted by Ciaian et al. (2016), who considered both the traditional determinants of currency price - supply and demand forces - and digital currency specific factor for investor's attractiveness.

Investors around the globe have witnessed an impressive growth in cryptocurrencies markets. ${ }^{2}$ Bitcoin, the first ever cryptocurrency and the most well-known in the market (Nguyen et al., 2018), displays a market cap close to US\$ 1 trillion. ${ }^{3}$ Although the magnitude of the volume aroused the curiosity of many scholars, bitcoin's price volatility is quite peculiar. It went from zero value at the time of its inception, in 2009, to around US\$1,100 4 years later. Then, the price dropped to around US $\$ 250$ at the end of 2014, before another exponential growth curve until almost reaching US\$20,000 in December, 2017. Such price movements are unusual for traditional currencies, suggesting that the determinants for price formation do not follow rules established in previous theories (Ciaian et al., 2016), or in the words of Mai et al. (2018) traditional explanatory variables for currency valuation fall short. Gemici and Polat (2019) find a unilateral causality relationship determined from negative shocks in bitcoin prices to negative shocks in trading volume 
as well as from positive shocks in trading volume to positive shocks in prices. Also, some studies found evidence that bitcoin prices are a financial bubble (Geuder et al., 2019, Chaim and Laurini, 2019). We approach the problem by studying the bitcoin market in Brazil, a large emerging economy with an unregulated bitcoin market.

If information flows freely, we should observe an equilibrium in price among exchanges, independently of the geographical location. Under some market efficiency, bitcoin prices should follow the Law of One Price (LOOP, hereafter). However, Pieters and Vivanco (2017) find evidence indicating violations of LOOP for bitcoin. After analyzing 11 distinct markets, representing $26 \%$ of the global market, evidence indicates that LOOP is not verified in markets where no compliance policy, such as mandatory user identification, is in place. This is the case we study, since in Brazil bitcoin exchanges are not subject to any regulation (BCB, 2020).

The study of financial markets has brought evidence that emerging economies have different markets from developed economies. In particular, Bekaert and Harvey (2002) review the empirical evidence and argue that emerging markets are relatively inefficient due to slow adjustment to new information. In addition, Cole et al. (2011) presents some evidence that high fixed costs of financial services can be a barrier to financial development. The market of cryptocurrencies has the potential to overcome such costs, since to operate in these markets one only needs access to the internet. Moreover, there is evidence that bitcoin markets can be efficient (Tiwari et al., 2018). Therefore, testing LOOP in the Brazilian bitcoin market can shed light on our knowledge about financial markets in emerging economies, and also on the behavior of bitcoin markets per se. Brazil is a particularly interesting case, as according to Bitcoin Average (https://bitcoinaverage.com) the Brazilian bitcoin market was ranked $4^{\text {th }}$ in the world in 2017.

Following the method of Pieters and Vivanco (2017), we conduct tests using data from three Brazilian exchanges to check whether bitcoin prices satisfy LOOP, even though no user identification rule is imposed through regulation, and some Brazilian bitcoin exchanges do not mandate it. We find a common trend within bitcoin prices among these different exchanges. First, we 
identify that prices are non-stationary in Brazilian markets. Next, we verify that the price series are cointegrated. The cointegration tests between the price series indicate that LOOP is valid in Brazilian markets in the long run.

However, there remains the question about bitcoin price dynamics in the short run. Mai et al. (2018) raise a relevant concern about bitcoin price formation: what determines its value? The answer concerns investors, who can profit from estimating future price swings and calculating expected returns. Bitcoin can be converted virtually to any fiat currency, such as USD, EUR, GBP, JPY, or BRL. With exchanges all over the globe operating $24 / 7$, with little to no regulation, can there be opportunities of arbitrage? Such opportunities could arise between countries, and between exchanges within the same country. Therefore, we also study the price discovery mechanism in Brazilian exchanges. Price discovery happens when new information is impounded into the implicit, efficient price, leading to a permanent change of its level (Hasbrouck, 1995). In the short run, one exchange could lead the other in price discovery, opening up opportunities for arbitrage between Brazilian exchanges. We use two distinct and complementary measures for price discovery (Baillie et al., 2002), Information Share (Hasbrouck, 1995), and Component Share (Gonzalo and Granger, 1995). We combine the two measures to obtain an Information Leadership Share (ILS) measure (Putniňš, 2013). ILS indicates that, for closing prices, the most liquid exchange (Foxbit) leads discovery, while the least liquid (Local Bitcoin) lags, with Mercado Bitcoin in the middle both in terms of discovery and liquidity.

There is evidence that some markets leads bitcoin price discovery. In an international context, Pagnottoni and Dimpfl (2018) find that Chinese exchanges leads bitcoin price discovery. Bitcoin futures market dominates the price discovery process in the US Kapar and Olmo (2019). To the best of our knowledge, our research brings the first evidence of a price discovery mechanism for exchanges in Brazilian Reais (BRL). The evidence we bring show that LOOP is valid in the long run, but reinforces existing evidence that inefficiencies in bitcoin markets still exist, potentially creating arbitrage opportunities (Kroeger and Sarkar, 2017, Köchling et al., 2018, Sensoy, 2018). 


\section{Data}

We use daily bitcoin price data spanning from December $11^{\text {th }}, 2014$ to February $8^{\text {th }}$, 2018, which amounts to 1,149 days. The initial date corresponds to the beginning of Foxbit exchange's price series. The end date is the last day available for which there is no missing data in the data source for all exchanges. ${ }^{4}$ We use Quandl's API to retrieve the prices. Quandl is a platform that collects several economics and finance time series, collecting bitcoin prices reported to Bitcoincharts.

The data we obtain come from 3 Brazilian exchanges: Local Bitcoin, Mercado Bitcoin, and Foxbit (see Table 1). Although there are other exchanges in Brazil, like NegocieCoins, Arena Bitcoin, and Bitcointoyou, we do not have access to their data. They do not report daily prices to Bitcoincharts, a platform that aggregates bitcoin data from all over the world, nor provide any means of getting daily prices directly from them.

Table 1: Selected Brazilian bitcoin exchanges

\begin{tabular}{lcl}
\hline Exchange & Num.Obs & URL \\
\hline Foxbit & 1,149 & https://foxbit.exchange \\
Mercado Bitcoin & 1,149 & https://www.mercadobitcoin.com.br \\
Local Bitcoin & 1,149 & https://localbitcoins.com.pt \\
\hline
\end{tabular}

All exchanges have daily prices from December $11^{\text {th }}, 2014$ to February $8^{\text {th }}, 2018$.

Of the 3 exchanges, Mercado Bitcoin does not clearly state whether it adopts some kind of knowyour-customer (KYC) or anti-money-laundering (AML) policy. These are important features for 
the validity of the Law of One Price (LOOP) (Pieters and Vivanco, 2017). In turn, both Local Bitcoin and Foxbit report to comply with KYC and AML policies. Table 2 presents the main characteristics of these exchanges regarding customer policies.

Table 2: Summary of exchanges' characteristics

\begin{tabular}{lrrrcc}
\hline Exchange & Trading fee & Deposit fee & Withdrawal fee & KYC & AML \\
\hline Foxbit & $0.25 \%$ to $0.50 \%$ & $0 \%$ & $1.39 \%$ or $1.39 \%+\mathrm{R} \$ 9.50$ & Yes & Yes \\
Mercado Bitcoin & $0.30 \%$ to $0.70 \%$ & $\mathrm{R} \$ 2.90+1.99 \%$ & $\mathrm{R} \$ 2.90 \$+\$ 1.99 \%$ & $?$ & $?$ \\
Local Bitcoin & $0 \%$ to $1 \%$ & $0.50 \%$ & $0.50 \%$ & Yes & Yes \\
\hline
\end{tabular}

KYC is know-your-customer policy, AML is anti-money-laundering policy. "?" indicates the exchange does not deny nor confirm enforcing a policy. BRL $\$ 1$ is approximately US\$0.18 as of Feb/2021.

Table 3 shows the averages for the data Quandl provides. There are opening and closing prices, highest and lowest intraday prices, and transaction volume. Unlike stock exchanges, bitcoin exchanges do not really have opening and closing times, since they operate $24 \mathrm{~h}$ per day, 7 days a week, non-stop. Therefore, closing price is the last trade recorded until 23h59min59sec UTC (Coordinated Universal Time), and the opening price is the first negotiation recorded from 0h00min00sec, UTC.

Note how average prices differ from one exchange to another. In particular, the High and Low prices of Local Bitcoin present a sizable difference when compared to the other exchanges. It may be a liquidity problem, as the average traded volume is much lower in Local Bitcoin. However, the other two exchanges also show signs of different prices, although to a smaller degree. Also note that Open and Close prices are potentially less than 1 second away from each other, and even so there are non-negligible differences within the same exchange. In conjunction, these numbers indicate a highly dynamic and volatile market, in which pricing can quickly change.

Figure 1 plots the opening price series for each of the exchanges. Their overall shapes are quite similar, with little visual differences. All of the series start at about BRL $\$ 1,000$, and fluctuate around this value until May/2017. In this month prices begin escalating, and reached about BRL $\$ 18,000$ on February $8^{\text {th }}$, 2018, in all exchanges. One difference worth noting is the larger 
Table 3: Average bitcoin prices and volume

\begin{tabular}{lrrrrr}
\hline Exchange & Open & Close & High & Low & Volume (BTC) \\
\hline Foxbit & 7488.72 & 7512.95 & 7764.94 & 7149.39 & 310.32 \\
Mercado Bitcoin & 7497.07 & 7524.90 & 7787.28 & 7125.75 & 204.01 \\
Local Bitcoin & 7793.94 & 7875.94 & 11400.54 & 6788.45 & 12.14 \\
\hline
\end{tabular}

Open is the "opening" price, the first trade recorded at 0h00min00sec UTC, Close is the "closing" price, the last trade recorded at $23 \mathrm{~h} 59$ min $59 \mathrm{sec}$ UTC, High is the highest intraday price, Low is the lowest intraday price, and Volume (BTC) is the total sum of all trades within the day, in bitcoins. All prices are in BRL per bitcoin. Sample period: December $11^{\text {th }}, 2014$ to February $8^{\text {th }}, 2018$.

volatility of Local Bitcoin, corroborating the analysis of Table 3. The graphs also show similar trends and behaviors: the series apparently are non-stationary, and seem to display comovement, indicating that these series may have a unit root and be cointegrated. Next we discuss how we formally test these properties.

\section{Methodology}

\subsection{Testing LOOP}

We use only the opening and closing prices series. The high and low prices can occur at different times of the day on each exchange, thus defeating the purpose of our study, since prices at different times can be related to different information sets. This rationale is especially true for bitcoin, since the cryptocurrency is traded continuously around the globe.

We use three distinct unit root tests. One of them uses the opposite null hypothesis of the others, thus increasing the power of our tests and reducing concerns of wrong inference (Kwiatkowski et al., 1992). The Augmented Dickey-Fuller (ADF) and Phillips-Perron (PP) test the null hypothesis of a unit root (Dickey and Fuller, 1979, Phillips and Perron, 1988). The Kwiatkowski-PhillipsSchmidt-Shin (KPSS) tests the null of stationarity (Kwiatkowski et al., 1992).

If the tests detect the existence of a unit root, the series can be tested for cointegration (Johansen, 1995). The test checks the existence of cointegration vectors, and indicates whether the 


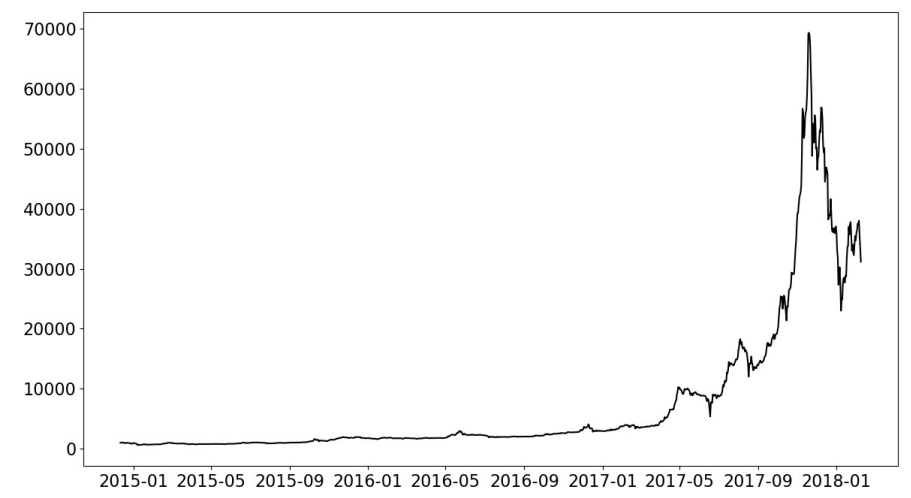

(b) Mercado Bitcoin

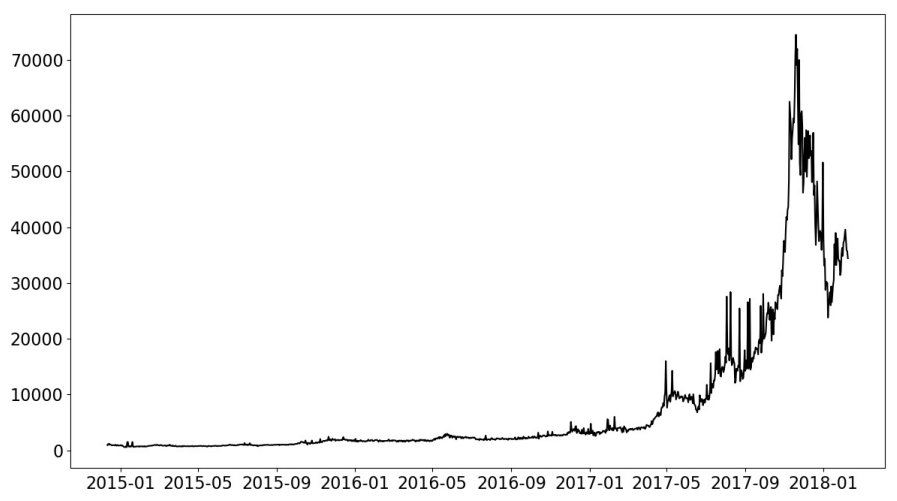

(c) Local Bitcoin

Figure 1: Bitcoin opening prices in Brazilian exchanges 


\subsection{Price discovery}

Returning to Equation (1), suppose that $\beta=1$ and therefore LOOP is valid. Since cointegration is a long run relation, we can have a disturbance at the price among different markets in the short run. Moreover, cointegration implies Granger causality between the prices at least in one direction (Enders, 2008). Then, one of the markets can lead price changes in the Brazilian market. There remains the question where price discovery occurs. Within the framework of Hasbrouck (1995), there is a common, implicit efficient price for the same asset traded in different markets. Same asset is defined broadly as assets "closely linked by arbitrage or short-term equilibrium considerations", such as an asset traded in different exchanges, or an asset and its derivative (Hasbrouck, 1995).

Price discovery happens when new information is impounded into the efficient price, leading to a permanent change in its level (Hasbrouck, 1995, Harris et al., 2002, Aggarwal and Thomas, 2018). One way of measuring it is through Information Share (IS), "defined as the proportion of the efficient price innovation variance that can be attributed" to one market (Hasbrouck, 1995). 
Implementation details can be found in Hasbrouck (1995) and Aggarwal (n.d.). We use it to test which exchange dictates price discovery by doing all permutations possible to estimate the upper and lower bounds of IS for each market.

Another way of measuring price discovery is through Component Share (CS). The measure is based on Gonzalo and Granger (1995)'s approach of obtaining common factors that are integrated of order 1. As Baillie et al. (2002) argue, CS complements IS, providing a different view of the price discovery process. Both models are based on VECMs (Vector Error Correction Models). However, the IS model works with variance, while the CS model is based on the contribution given by the market's error correction coefficients to the common factor (Baillie et al., 2002, Harris et al., 2002). One important feature of CS is that it "isolates the dynamics following a synchronous event of price divergence (...) and the subsequent readjustment to a common stochastic trend" (Harris et al., 2002).

Baillie et al. (2002) exemplify this isolation property of CS. Consider an asset traded in two different markets, with highly correlated and cointegrated prices. The first market's price responds to deviations from the second market's price, but the opposite is not true: the second market's price does not respond to the first. According to the CS model, price discovery happens on the second market. However, the IS model suggests the two markets contribute to price discovery, since they are highly correlated.

Yan and Zivot (2010) discuss what IS and CS really measure. One result is that IS can yield ambiguous interpretations, as Baillie et al. (2002) discuss. However, Yan and Zivot (2010) also show that CS "measures the relative response to contemporaneous transitory frictions", concluding that CS does not measure responses to new information but the level of noise in one price series relative to the other (Putnin̦š, 2013). To overcome these issues, we follow Putniňš (2013) and calculate the Information Leadership Share (ILS), defined as in Equation (3). 


$$
\begin{aligned}
I L_{1} & =\left|\frac{I S_{1}}{I S_{2}} \cdot \frac{C S_{2}}{C S_{1}}\right|, & I L_{2} & =\left|\frac{I S_{2}}{I S_{1}} \cdot \frac{C S_{1}}{C S_{2}}\right| \\
I L S_{1} & =\frac{I L_{1}}{I L_{1}+I L_{2}}, & I L S_{2} & =\frac{I L_{2}}{I L_{1}+I L_{2}}
\end{aligned}
$$

In which $I L_{k}, I S_{k}$, and $C S_{k}$ are market's $k$ Information Leadership metric, Information Share, and Component Share, respectively. As $I S_{k}$ depends on the ordering of the price series, we also follow Baillie et al. (2002) and use the simple average between IS and Reverse IS as $I S_{k}$. Note that $I L_{k} \in[0, \infty)$, unlike $I S_{k}$ and $C S_{k}$, which lie in the interval $[0,1]$. Therefore, we normalize to an Information Leadership Share $\left(I L S_{k}\right)$.

\section{Results}

Table 4 presents results for the unit root test. They indicate both opening and closing price series are non-stationary. The only exception is the PP test for the Local Bitcoin exchange closing price series. Therefore, we consider that prices exhibit non-stationarity in all exchanges.

We also test whether the first difference series has a unit root (Table 5). Note how all series are stationary in all tests. In conjunction with Table 4, we conclude that all the bitcoin price series we use are integrated of order $1, I(1)$. Therefore, we can proceed to test their cointegration (Johansen, 1995).

Table 6 shows the cointegration test. Note that we test the three exchanges in pairs, yielding $C(3,2)=3$ test statistics. The test for $\operatorname{Rank}=0$ rejects the null of no cointegration, while the test for $R a n k=1$ does not reject the null that the pair is cointegrated, both for the closing and opening prices. Therefore, we conclude all pairs of series are cointegrated.

More important, closing price series, as well as the opening price series, share one common trend and consequently, move in tandem in the long term. Note that the cointegration test between 
Table 4: Unit root tests

\begin{tabular}{lccc}
\hline \multicolumn{3}{c}{ Closing prices } \\
\hline & Foxbit & Mercado Bitcoin & Local Bitcoin \\
Lags & 1 & 1 & 6 \\
ADF & -2.40 & -2.07 & -2.13 \\
PP & -2.186 & -2.109 & $-5.318^{*}$ \\
KPSS & $2.6^{*}$ & $2.58^{*}$ & $2.62 *$ \\
\hline & & Opening prices & \\
\hline & Foxbit & Mercado Bitcoin & Local Bitcoin \\
Lags & 1 & 1 & 7 \\
ADF & -2.12 & -2.03 & -1.95 \\
PP & -2.146 & -2.076 & -3.247 \\
KPSS & $2.6^{*}$ & $2.58^{*}$ & $2.6 *$
\end{tabular}

* is significant at $1 \%$. All tests include a constant and a deterministic trend. ADF is the Augmented Dickey-Fuller test and PP is the Phillips-Perron test. These two test the null hypothesis of a unit root (non-stationarity). KPSS is the Kwiatkowski-PhillipsSchmidt-Shin test, which has a null of no unit root (stationarity). Number of lags determined by the Johansen procedure using the AIC (Johansen, 1995).

Table 5: Unit root tests: first difference

\begin{tabular}{|c|c|c|c|}
\hline \multicolumn{4}{|c|}{ Closing prices } \\
\hline & Foxbit & Mercado Bitcoin & Local Bitcoin \\
\hline Lags & 7 & 2 & 10 \\
\hline $\mathrm{ADF}$ & $-30.469 *$ & $-29.630 *$ & $-55.074^{*}$ \\
\hline $\mathrm{PP}$ & $-30.459 *$ & $-29.717 *$ & $-83.512^{*}$ \\
\hline KPSS & 0.043 & 0.043 & 0.018 \\
\hline \multicolumn{4}{|c|}{ Opening prices } \\
\hline & Foxbit & Mercado Bitcoin & Local Bitcoin \\
\hline Lags & 1 & 2 & 8 \\
\hline $\mathrm{ADF}$ & $-29.113 *$ & $-29.296 *$ & $-48.227^{*}$ \\
\hline PP & $-29.075^{*}$ & $-29.385 *$ & $-54.268^{*}$ \\
\hline KPSS & 0.042 & 0.043 & 0.031 \\
\hline
\end{tabular}

$*$ is significant at $1 \%$. All tests include a constant and a deterministic trend. ADF is the Augmented Dickey-Fuller test and PP is the PhillipsPerron test. These two test the null hypothesis of a unit root (nonstationarity). KPSS is the Kwiatkowski-Phillips-Schmidt-Shin test, which has a null of no unit root (stationarity). The first difference is the series $F D_{t}^{y}=P_{t}^{y}-P_{t-1}^{y}$ for each exchange $y$. Number of lags determined by the Johansen procedure using the AIC (Johansen, 1995). 
Table 6: Johansen cointegration test

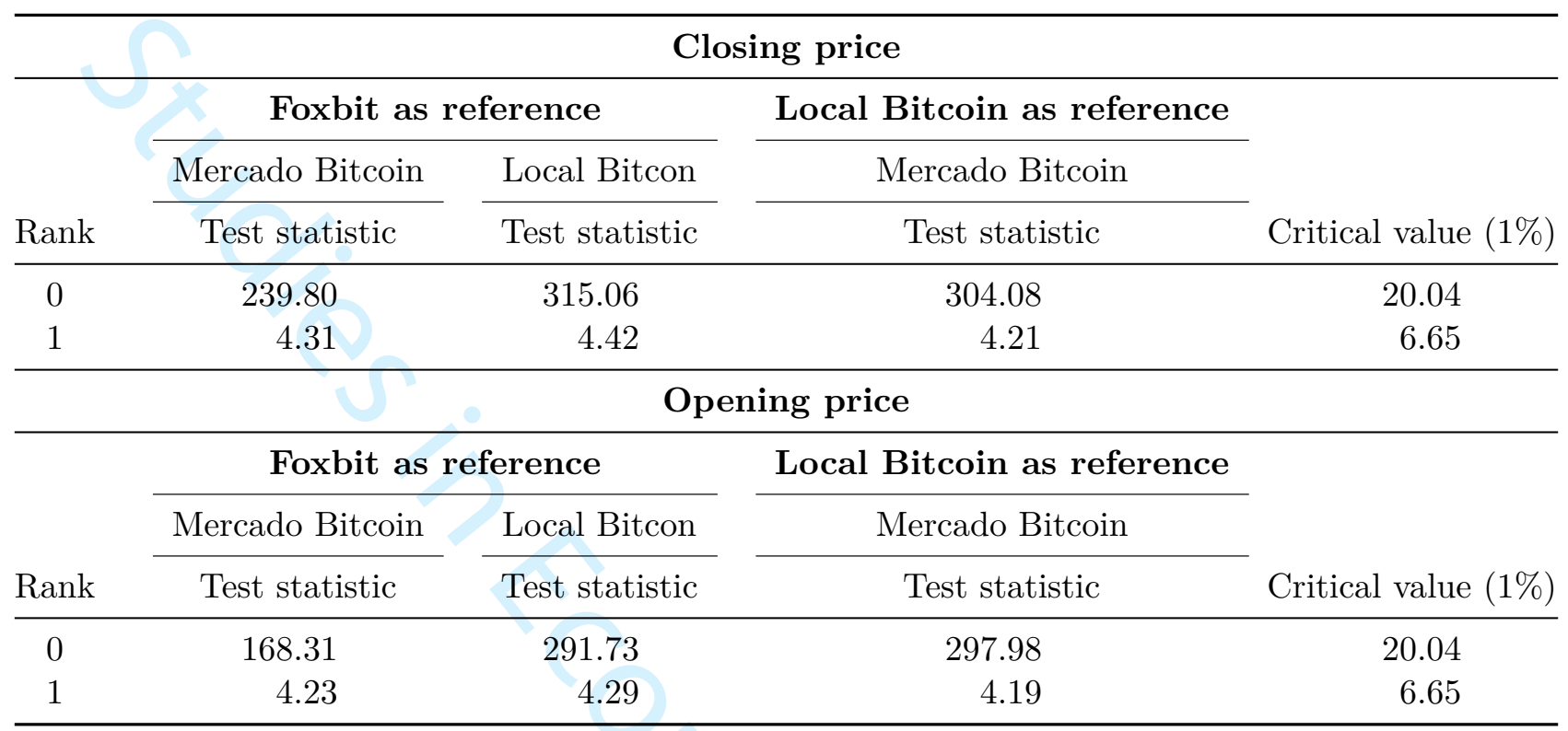

The test statistic is Johansen's trace statistic, $\lambda_{\text {trace }}$, under the null hypothesis that the rank of the matrix of coefficients of the vector auto-regression is 0 (no cointegration) or 1 (cointegraton between two series). Series are tested in pairs: (Foxbit, Mercado Bitcoin), (Foxbit, Local Bitcoin), and (Local Bitcoin, Mercado Bitcoin). Critical values come from Johansen (1995).

Mercado Bitcoin and Local Bitcoin prices is not necessary, since they both share a trend with Foxbit (Stock and Watson, 1988). However, we conduct the test anyway, since our question is not about cointegration only. We also want details on the cointegration vectors, to recover the estimated $\beta$ from Equation (1), shown in Table 7. The evidence indicates that the Law of One Price is valid between these three Brazilian bitcoin exchanges, since all of the $\hat{\beta}_{\mathrm{s}}$ are close to 1. Therefore, in the long term prices converge to the same value between these exchanges. However, this may not be true in the short term, which we explore next.

\subsection{Price discovery in Brazil}

Table 8 shows results using Information Share (IS) and Component Share (CS) techniques with the three possible pairs combining the three exchanges. Since IS depends on the ordering of price variables (Aggarwal, n.d., Baillie et al., 2002), Table 8 also shows the Reverse IS. The IS value we use to calculate the ILS advocated by Putniņš (2013) is the simple mean between IS and Reverse 
Table 7: Cointegration and Law of One Price

\begin{tabular}{|c|c|c|c|}
\hline \multicolumn{4}{|c|}{ Closing price } \\
\hline & \multicolumn{2}{|c|}{ Foxbit as reference } & Mercado Bitcoin as reference \\
\hline & Mercado Bitcoin & Local Bitcoin & Local Bitcoin \\
\hline Cointegrate? & Yes & Yes & Yes \\
\hline$\hat{\beta}$ & $1.00 *$ & $0.99^{*}$ & $1.00^{*}$ \\
\hline \multirow[t]{4}{*}{ LOOP? } & Yes & Yes & Yes \\
\hline & $\sqrt{3}$ & Opening price & \\
\hline & \multicolumn{2}{|c|}{ Foxbit as reference } & Mercado Bitcoin as reference \\
\hline & Mercado Bitcoin & Local Bitcoin & Local Bitcoin \\
\hline Cointegrate? & Yes & Yes & Yes \\
\hline$\hat{\beta}$ & $1.00^{*}$ & $1.00^{*}$ & $0.99^{*}$ \\
\hline LOOP? & Yes & Yes & Yes \\
\hline
\end{tabular}

$*$ is significant at $1 \%$. Cointegrate? indicates if the series cointegrate according to the Johansen test; $\hat{\beta}$ is the estimated $\beta$ from Equation (1); LOOP? indicates if Law of One Price is valid.

IS.

The Mean IS estimate indicates that Mercado Bitcoin (MB) leads price discovery. Ordering the inequalities, we obtain that MB leads, Foxbit (FB) stands in the middle, and Local Bitcoin (LB) lags discovery. CS tells a similar story, with Mercado Bitcoin leading discovery in Brazil. This is consistent with LB being by far the less liquid exchange, with a volume less than a tenth of MB or FB (see Table 3). The difference between FB and MB is much lower, with FB trading 1.5 times the volume of MB. However, in this case, the less liquid exchange leads price discovery.

Results taking into account for IS and CS simultaneously through ILS tell us a different story. For the closing prices, the ordering is inconsistent. ILS implies LB both leads and lags the other exchanges. Opening prices tell a more consistent story, although different from IS and CS. Both FB and MB lead LB, consistent with IS and CS. But here FB leads MB, resulting in FB - MB - LB ordering of price discovery. Thus, ILS estimates for closing prices follow the ordering of liquidity with the most liquid exchange leading and the least liquid lagging discovery.

The disagreement between the isolated measures, IS and CS, and the integrated measure, ILS, 
Table 8: Price discovery

\begin{tabular}{lccccc}
\hline \multicolumn{5}{c}{ Closing price } \\
\hline Exchange & IS & Reverse IS & Mean IS & CS & ILS \\
\hline Mercado Bitcoin & 0.943 & 0.281 & 0.612 & 0.697 & 0.319 \\
Foxbit & 0.056 & 0.718 & 0.387 & 0.302 & $\mathbf{0 . 6 8 1}$ \\
Mercado Bitcoin & 0.986 & 0.981 & 0.984 & 0.963 & $\mathbf{0 . 8 4 9}$ \\
Local Bitcoin & 0.013 & 0.018 & 0.016 & 0.036 & 0.151 \\
Local Bitcoin & 0.045 & 0.001 & 0.023 & 0.013 & $\mathbf{0 . 7 6 2}$ \\
Foxbit & 0.954 & 0.998 & 0.976 & 0.986 & 0.238 \\
\hline & \multicolumn{7}{c}{ Opening price } & & \\
\hline Exchange & IS & Reverse IS & Mean IS & CS & ILS \\
\hline Mercado Bitcoin & 0.883 & 0.312 & 0.598 & 0.622 & 0.449 \\
Foxbit & 0.116 & 0.687 & 0.402 & 0.377 & $\mathbf{0 . 5 5 1}$ \\
Mercado Bitcoin & 0.911 & 0.976 & 0.944 & 0.859 & $\mathbf{0 . 8 8 5}$ \\
Local Bitcoin & 0.088 & 0.023 & 0.056 & 0.140 & 0.115 \\
Local Bitcoin & 0.078 & 0.049 & 0.064 & 0.110 & 0.231 \\
Foxbit & 0.921 & 0.950 & 0.936 & 0.889 & $\mathbf{0 . 7 6 9}$ \\
\hline
\end{tabular}

IS is Information Share (Hasbrouck, 1995). Reverse IS the same as IS, but reversing the price order (Aggarwal, n.d., Baillie et al., 2002). Mean IS is the arithmetic mean between IS and Reverse IS (Baillie et al., 2002). CS is Component Share (Baillie et al., 2002, Harris et al., 2002, Gonzalo and Granger, 1995). ILS is Information Leadership share, calculated as in Equation (3) aggregating both IS and CS measures (Yan and Zivot, 2010, Putniņ̌s, 2013). A larger ILS indicates that the series leads price discovery, as indicated by numbers in bold. 
is consistent with Putniňš (2013) and Yan and Zivot (2010) suggestions that IS can be ambiguous, and CS measures level of noise. For the opening prices, there is a correlation between liquidity and price discovery as measured by ILS. It indicates that arbitrageurs might use Foxbit's price to generate opportunities. However, as the LOOP test indicates, these opportunities disappear over time.

Our findings go in line with Brandvold et al. (2015), who document that certain exchanges lead others in price discovery, but they only include exchanges denominated in US Dollars, Chinese Yuans, Polish Zlotys, and Canadian Dollars. To the best of our knowledge, our result is the first to point a price discovery mechanism for exchanges denominated in Brazilian Reais. Our result is also consistent with Makarov and Schoar (2018), who find that arbitrage opportunities can persist for days or even weeks in the US, Japan, and Korea. We document that the same opportunities may exist in the Brazilian market, reinforcing evidence that the bitcoin market still has inefficiencies, although it has been improving (Köchling et al., 2019, Sensoy, 2018). Next, we show how this possibility may be explored.

\subsection{A trading strategy based on price discovery}

We consider the following algorithm to explore the possibility of arbitrage. We take the ILS as a measure to indicate which exchange leads the price discovery. For any pair of exchanges, we define the exchange with the highest ILS as the leader and the other one as the follower. Then, we use the information of price movements in the leader to make 'transactions' in the follower using the historical data as follows:

1. Start an account in the follower exchange with 0 bitcoin in the first period;

2. Wait until a period $t$ where $\Delta P_{t}^{\text {leader }}=P_{t}^{\text {leader }}-P_{t-1}^{\text {leader }}>0$ (i.e., there is a price increase in the leader exchange) and buy one bitcoin in the follower exchange;

3. In the next period, keep the bitcoin if $\Delta P_{t}^{\text {leader }}>0$ (i.e., price keeps increasing in the leader 


\section{$5 \quad$ Final Remarks}

We contribute to the knowledge of bitcoin price behavior in a large emerging market, Brazil. Bitcoin evidence in non-developed markets is relatively scarce, despite the importance of such markets (Carrick, 2016, Ferreira Frascaroli and Carvalho Pinto, 2016). To the best of our knowledge, our research brings the first evidence of a price discovery mechanism for exchanges in Brazilian Reais. The evidence we bring show that LOOP is valid in the long run, but reinforces existing evidence that inefficiencies in bitcoin markets still exist, potentially creating arbitrage opportunities 
Table 9: Gross profit comparison

\begin{tabular}{|c|c|c|c|}
\hline \multicolumn{4}{|c|}{ Closing price } \\
\hline Exchage & Leader & Leadership arbitrage & Buy-and-hold \\
\hline $\begin{array}{l}\text { Foxbit } \\
\text { Mercado Bitcoin }\end{array}$ & $\mathrm{X}$ & BRL $\$ 34,108.21$ & BRL\$ 30,314.11 \\
\hline $\begin{array}{l}\text { Mercado Bitcoin } \\
\text { Local Bitcoin }\end{array}$ & $\mathrm{X}$ & & BRL $\$ 29,748.84$ \\
\hline $\begin{array}{l}\text { Local Bitoin } \\
\text { Foxbit }\end{array}$ & $\mathrm{X}$ & BRL $\$ 13,928.10$ & BRL\$ 29,897.31 \\
\hline \multicolumn{4}{|c|}{ Opening price } \\
\hline Exchage & Leader & Leadership arbitrage & Buy-and-hold \\
\hline $\begin{array}{l}\text { Foxbit } \\
\text { Mercado Bitcoin }\end{array}$ & $\mathrm{X}$ & $\mathrm{BRL} \$ 34,414.33$ & BRL\$ 29,995.95 \\
\hline $\begin{array}{l}\text { Mercado Bitcoin } \\
\text { Local Bitcoin }\end{array}$ & $\mathrm{X}$ & BRL $\$ 33,670.05$ & BRL $\$ 33,140.89$ \\
\hline $\begin{array}{l}\text { Foxbit } \\
\text { Local Bitoin }\end{array}$ & $\mathrm{X}$ & BRL $\$ 57,252.78$ & BRL $\$ 33,140.89$ \\
\hline
\end{tabular}

The "X" indicates the leader exchange according to Table 8, i.e., the exchange with the largest ILS. Gross profit is net of average trading fees, but does not account for other fees such as deposit and withdraw fees. 
(Kroeger and Sarkar, 2017, Köchling et al., 2018, Sensoy, 2018).

Finally, understanding cryptocurrencies price formation is a hard task. Those assets are special in many senses - there are multiple parallel markets, which never close, operating in many countries, where you can trade using different fiat currencies. Our work sheds some light on the matter of bitcoin price dynamics. Our results indicates that using information of price variations in certain markets can be used to trade in another market. Investors and researchers can try to explore similar strategies in the cryptocurrency markets by looking at data with a higher frequency or even looking at price discovery between different cryptocurrencies.

\section{Notes}

${ }^{1}$ Bitcoin mining is the process of confirming transaction by writing then in a block to be added to the blockchain. For more details on bitcoin mining see Narayanan et al. (2016).

${ }^{2}$ Many works studied the use of cryptocurrencies in portfolios. For examples, see Leung and Nguyen (2019) and Brauneis and Mestel (2019).

${ }^{3}$ See in accord to https://coinmarketcap.com/currencies/bitcoin/, accessed on February 19th, 2021.

${ }^{4}$ After February 8th, 2018, there are missing data on Closing/Opening Prices for the Local Bitcoin exchange.

${ }^{5}$ Note that our strategy is not risk-free in the sense of a "classical" arbitrage as defined by Hull (2012, p.15). By construction it is a risky strategy, since we buy the asset and carry it for at least one day in our portfolio and there is no other simultaneous transaction.

${ }^{6}$ Shynkevich (2020) studies markets where bitcoin is traded but denominated in US dollars, and reports that profitable arbitrage opportunities have become sparse and scarce since 2018. In fact, in the online appendix we present an exercise where we use our strategy in more recent data, and results indicate that the buy-and-hold strategy yields a higher gross return. These results are consistent with the empirical evidence of Crépelière and Zeisberger (2020) and Shynkevich (2020). 


\section{References}

Aggarwal, N. (n.d.), Information share and component share weights: R implementation, Technical report, Indira Gandhi Institute of Development Research.

URL: https://rdrr.io/rforge/ifrogs/f/inst/doc/pdshare.pdf

Aggarwal, N. and Thomas, S. (2018), 'When stock futures dominate price discovery', Journal of Futures Markets 39(3), 263-278.

Baillie, R. T., Booth, G. G., Tse, Y. and Zabotina, T. (2002), 'Price discovery and common factor models', Journal of Financial Markets 5(3), 309-321.

BCB (2020), 'Perguntas e respostas: Moedas virtuais', Webpage.

URL: $\quad$ Gttps://www.bcb.gov.br/acessoinformacao/perguntasfrequentesrespostas/faq_moedasvirtuais

Bekaert, G. and Harvey, C. R. (2002), 'Research in emerging markets finance: looking to the future', Emerging markets review 3(4), 429-448.

Brandvold, M., Molnár, P., Vagstad, K. and Valstad, O. C. A. (2015), 'Price discovery on bitcoin exchanges', Journal of International Financial Markets, Institutions and Money 36, 18-35.

Brauneis, A. and Mestel, R. (2019), 'Cryptocurrency-portfolios in a mean-variance framework', Finance Research Letters 28, 259-264.

Carrick, J. (2016), 'Bitcoin as a complement to emerging market currencies', Emerging Markets Finance and Trade 52(10), 2321-2334.

Chaim, P. and Laurini, M. P. (2019), 'Is bitcoin a bubble?', Physica A: Statistical Mechanics and its Applications 517, 222-232.

Ciaian, P., Rajcaniova, M. and Kancs, d. (2016), 'The economics of BitCoin price formation', Applied Economics 48(19), 1799-1815. 
Cole, S., Sampson, T. and Zia, B. (2011), 'Prices or knowledge? What drives demand for financial services in emerging markets?', The Journal of Finance 66(6), 1933-1967.

Crépelière, T. and Zeisberger, S. (2020), Arbitrage in the market for cryptocurrencies. Available at SSRN 3606053.

Dickey, D. A. and Fuller, W. A. (1979), 'Distribution of the estimators for autoregressive time series with a unit root', Journal of the American Statistical Association 74(366a), 427-431.

Enders, W. (2008), Applied Econometric Time Series, John Wiley \& Sons.

Ferreira Frascaroli, B. and Carvalho Pinto, T. (2016), 'Aspectos inovativos do bitcoin, microestrutura de mercado e volatilidade de retornos.', Revista Brasileira de Economia de Empresas/Brazilian Journal of Business Economics 16(2), 49-70.

Gemici, E. and Polat, M. (2019), 'Relationship between price and volume in the bitcoin market', The Journal of Risk Finance 20(5), 435-444.

Geuder, J., Kinateder, H. and Wagner, N. F. (2019), 'Cryptocurrencies as financial bubbles: The case of bitcoin', Finance Research Letters 31.

Gonzalo, J. and Granger, C. (1995), 'Estimation of common long-memory components in cointegrated systems', Journal of Business \& Economic Statistics 13(1), 27-35.

Harris, F. H. B., McInish, T. H. and Wood, R. A. (2002), 'Security price adjustment across exchanges: an investigation of common factor components for dow stocks', Journal of Financial Markets 5(3), 277-308.

Hasbrouck, J. (1995), 'One security, many markets: Determining the contributions to price discovery', The Journal of Finance 50(4), 1175-1199.

Hull, J. (2012), Options, futures, and other derivatives, 8th ed edn, Prentice Hall. 
Johansen, S. (1995), Likelihood-Based Inference in Cointegrated Vector Autoregressive Models, Oxford University Press.

Kapar, B. and Olmo, J. (2019), 'An analysis of price discovery between bitcoin futures and spot markets', Economics Letters 174, 62-64.

Karame, G. (2016), On the security and scalability of bitcoin's blockchain, in 'Proceedings of the 2016 ACM SIGSAC conference on computer and communications security', ACM, pp. 18611862.

Köchling, G., Müller, J. and Posch, P. N. (2018), 'Does the introduction of futures improve the efficiency of Bitcoin?', Finance Research Letters .

Köchling, G., Müller, J. and Posch, P. N. (2019), 'Price delay and market frictions in cryptocurrency markets', Economics Letters 174, 39-41.

Kristoufek, L. (2015), 'What are the main drivers of the Bitcoin price? Evidence from wavelet coherence analysis', PloS One 10(4), e0123923.

Kroeger, A. and Sarkar, A. (2017), The Law of One Bitcoin Price? Federal Reserve Bank of Philadelphia.

Kwiatkowski, D., Phillips, P. C., Schmidt, P. and Shin, Y. (1992), 'Testing the null hypothesis of stationarity against the alternative of a unit root', Journal of Econometrics 54(1-3), 159-178.

Leung, T. and Nguyen, H. (2019), 'Constructing cointegrated cryptocurrency portfolios for statistical arbitrage', Studies in Economics and Finance 36(4), 581-599.

Mai, F., Shan, Z., Bai, Q., Wang, X. and Chiang, R. H. (2018), 'How does social media impact bitcoin value? A test of the silent majority hypothesis', Journal of Management Information Systems 35(1), 19-52. 
Makarov, I. and Schoar, A. (2018), Trading and Arbitrage in Cryptocurrency Markets, SSRN Scholarly Paper ID 3171204, Rochester, NY.

URL: https://papers.ssrn.com/abstract=3171204

Narayanan, A., Bonneau, J., Felten, E., Miller, A. and Goldfeder, S. (2016), Bitcoin and cryptocurrency technologies: a comprehensive introduction, Princeton University Press.

Nguyen, T., de Bodisco, C. and Thaver, R. (2018), 'Factor affection Bitcoin price in the cryptocurrencies market: an empirical study', International Journal of Business $\&$ Economics Perspectives $13(1)$.

Pagnottoni, P. and Dimpfl, T. (2018), Price Discovery on Bitcoin Markets, SSRN Scholarly Paper ID 3280261, Rochester, NY.

URL: https://papers.ssrn.com/abstract=3280261

Phillips, P. C. B. and Perron, P. (1988), 'Testing for a unit root in time series regression', Biometrika 75(2), 335-346.

Pieters, G. and Vivanco, S. (2017), 'Financial regulations and price inconsistencies across bitcoin markets', Information Economics and Policy 39, 1-14.

Poon, J. and Dryja, T. (2016), The bitcoin lightning network: Scalable off-chain instant payments.

Putniṇš, T. J. (2013), 'What do price discovery metrics really measure?', Journal of Empirical Finance 23, 68-83.

Sensoy, A. (2018), 'The inefficiency of bitcoin revisited: A high-frequency analysis with alternative currencies', Finance Research Letters 28, 68-73.

Shynkevich, A. (2020), 'Bitcoin arbitrage', Finance Research Letters p. 101698.

Stock, J. H. and Watson, M. W. (1988), 'Variable trends in economic time series', Journal of Economic Perspectives 2(3), 147-174. 
Tiwari, A. K., Jana, R., Das, D. and Roubaud, D. (2018), 'Informational efficiency of Bitcoin - An extension', Economics Letters 163, 106-109.

Yan, B. and Zivot, E. (2010), 'A structural analysis of price discovery measures', Journal of Financial Markets 13(1), 1-19. 
March 15, 2021

\begin{abstract}
In this online appendix, we apply our tests of LOOP and Price Discovery to a different dataset. The data used covers three Brazilian exchanges: Mercado Bitcoin, Braziliex, and BitcoinTrade from October 17th, 2017 to February 2nd, 2021. The results indicates that LOOP is valid among those exchanges, and Price Discovery measures indicates that exchange with higher volume of bitcoin transactions lead the price discovery in most of the cases.

Figure 1 and Tables 1 and 2 presents a general description of the data. Tables 3 and 4 present cointegration tests and LOOP indication respectively. Price Discovery measures as shown in Table 5. Finally, Table 6 presents a comparison of the gross profit between our leadership arbitrage and the buy-and-hold strategy.
\end{abstract}




\section{Data characteristics}

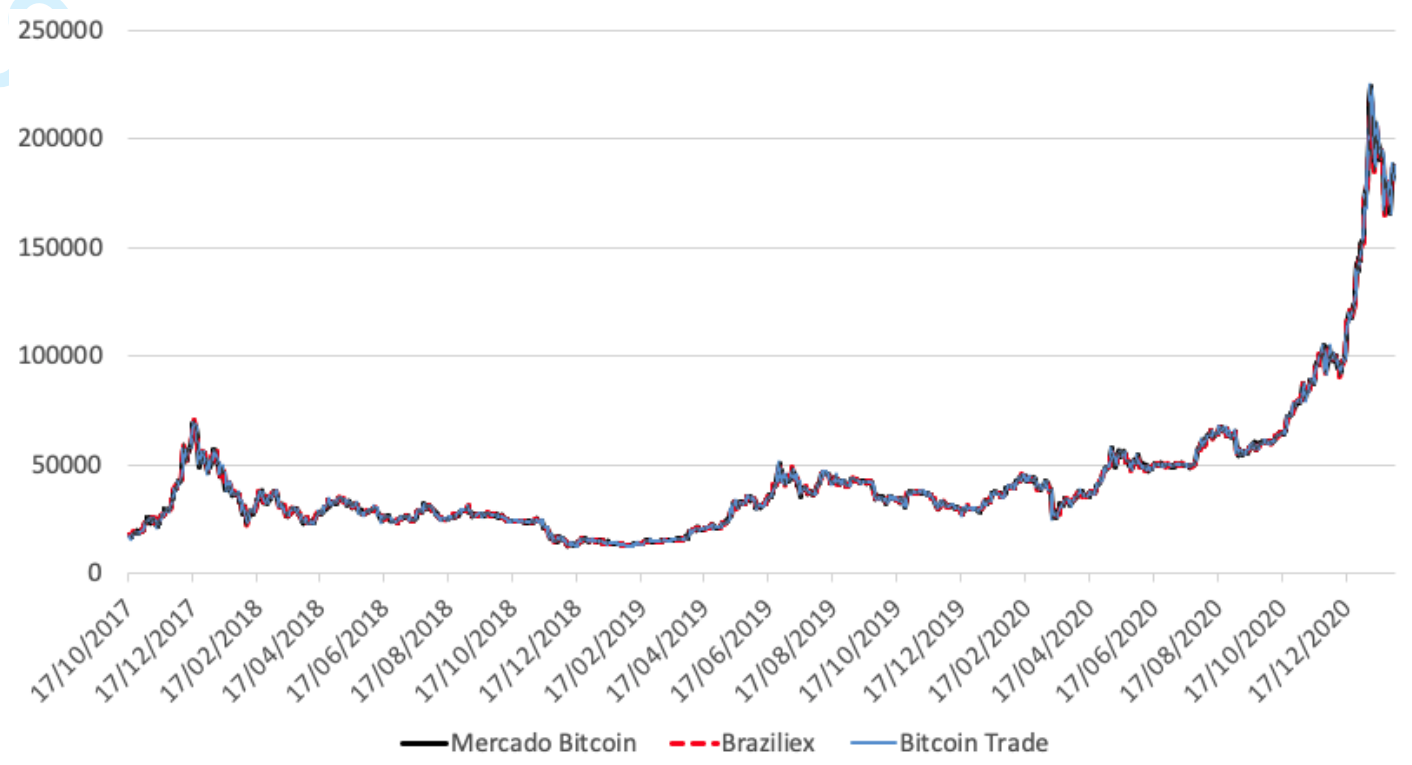

Figure 1: Bitcoin opening prices in BLR - selected Brazilian exchanges

Table 1: Summary of exchanges' characteristics

\begin{tabular}{|c|c|c|c|c|c|}
\hline Exchange & Trading fee & Deposit fee & Withdrawal fee & $\mathrm{KYC}$ & AML \\
\hline Mercado Bitcoin & $0.30 \%$ to $0.70 \%$ & $\mathrm{R} \$ 2.90+1.99 \%$ & $\mathrm{R} \$ 2.90 \$+\$ 1.99 \%$ & $?$ & $?$ \\
\hline BitcoinTrade & $0.25 \%$ to $0.50 \%$ & $0 \%$ & $\mathrm{R} \$ 4.90+0.99 \%$ & Yes & Yes \\
\hline Braziliex & $0.50 \%$ & $0 \%$ & $\mathrm{R} \$ 9.00+0.75 \%$ & Yes & Yes \\
\hline
\end{tabular}

KYC is know-your-customer policy, AML is anti-money-laundering policy. "?" indicates the exchange does not deny nor confirm enforcing a policy. BRL $\$ 1$ is approximately US $\$ 0.18$ as of Feb/2021. 
Table 2: Average prices and volume

Close

\section{Testing LOOP}

Table 3: Johansen cointegration test

\begin{tabular}{|c|c|c|c|c|}
\hline \multicolumn{5}{|c|}{ Closing price } \\
\hline & \multicolumn{2}{|c|}{ Mercado Bitcoin as reference } & \multirow{2}{*}{$\begin{array}{c}\text { BitcoinTrade as reference } \\
\text { Braziliex }\end{array}$} & \multirow[b]{3}{*}{ Critical value (1\%) } \\
\hline \multirow[b]{2}{*}{ Rank } & BitcoinTrade & Braziliex & & \\
\hline & Test statistic & Test statistic & Test statistic & \\
\hline 0 & 331.06 & 501.78 & 457.94 & 30.45 \\
\hline 1 & 5.42 & 7.06 & 7.01 & 16.26 \\
\hline \multicolumn{5}{|c|}{ Opening price } \\
\hline & \multicolumn{2}{|c|}{ Mercado Bitcoin as reference } & BitcoinTrade as reference & \\
\hline & BitcoinTrade & Braziliex & Braziliex & \\
\hline Rank & Test statistic & Test statistic & Test statistic & Critical value $(1 \%)$ \\
\hline 0 & 333.99 & 479.74 & 429.88 & 30.45 \\
\hline 1 & 5.29 & 7.32 & 6.95 & 16.26 \\
\hline
\end{tabular}

The test statistic is Johansen's trace statistic, $\lambda_{\text {trace }}$, under the null hypothesis that the rank of the matrix of coefficients of the vector auto-regression is 0 (no cointegration) or 1 (cointegraton between two series). Series are tested in pairs: (Foxbit, Mercado Bitcoin), (Foxbit, Local Bitcoin), and (Local Bitcoin, Mercado Bitcoin). Critical values come from Johansen (1995). 
Table 4: Cointegration and Law of One Price

\begin{tabular}{|c|c|c|c|}
\hline \multicolumn{4}{|c|}{ Closing price } \\
\hline & \multicolumn{2}{|c|}{ Mercado Bitcoin as reference } & BitcoinTrade as reference \\
\hline & BitcoinTrade & Braziliex & Braziliex \\
\hline \multirow{6}{*}{$\begin{array}{l}\text { Cointegrate? } \\
\hat{\beta} \\
\text { LOOP? }\end{array}$} & Yes & Yes & Yes \\
\hline & $0.99^{*}$ & $1.00^{*}$ & $1.00 *$ \\
\hline & Yes & Yes & Yes \\
\hline & \multicolumn{2}{|c|}{ Opening price } & \\
\hline & \multicolumn{2}{|c|}{ Mercado Bitcoin as reference } & BitcoinTrade as reference \\
\hline & BitcoinTrade & Braziliex & Braziliex \\
\hline Cointegrate? & Yes & Yes & Yes \\
\hline$\hat{\beta}$ & $0.99^{*}$ & $1.00^{*}$ & $1.00^{*}$ \\
\hline LOOP? & Yes & Yes & Yes \\
\hline
\end{tabular}

$*$ is significant at $1 \%$. Cointegrate indicates if the series cointegrate according to the Johansen test; $\hat{\beta}$ is the estimated $\beta$ from Equation ??; LOOP indicates if Law of One Price is valid.

\section{Price discovery measures}


Table 5: Price discovery

\begin{tabular}{lccccc}
\hline \multicolumn{5}{c}{ Closing price } \\
\hline Exchange & IS & Reverse IS & Mean IS & CS & ILS \\
\hline Mercado Bitcoin & 0.846 & 0.319 & 0.582 & 0.590 & 0.484 \\
BitcoinTrade & 0.153 & 0.680 & 0.416 & 0.409 & 0.515 \\
Mercado Bitcoin & 0.927 & 0.008 & 0.467 & 0.271 & 0.848 \\
Braziliex & 0.07 & 0.991 & 0.530 & 0.728 & 0.151 \\
BitcoinTrade & 0.726 & 0.035 & 0.378 & 0.282 & 0.707 \\
Braziliex & 0.273 & 0.964 & 0.618 & 0.717 & 0.292 \\
\hline & \multicolumn{7}{c}{ Opening price } & & \\
\hline Exchange & IS & Reverse IS & Mean IS & CS & ILS \\
\hline Mercado Bitcoin & 0.809 & 0.374 & 0.591 & 0.583 & 0.517 \\
BitcoinTrade & 0.190 & 0.625 & 0.407 & 0.416 & 0.482 \\
Mercado Bitcoin & 0.845 & 0.001 & 0.422 & 0.07 & 0.989 \\
Braziliex & 0.154 & 0.999 & 0.576 & 0.929 & 0.01 \\
BitcoinTrade & 0.575 & 0.104 & 0.064 & 0.348 & 0.016 \\
Braziliex & 0.424 & 0.895 & 0.936 & 0.651 & 0.983 \\
\hline
\end{tabular}

IS is Information Share (Hasbrouck, 1995). Reverse IS the same as IS, but reversing the price order (Aggarwal, n.d., Baillie et al., 2002). Mean IS is the arithmetic mean between IS and Reverse IS (Baillie et al., 2002). CS is Component Share (Baillie et al., 2002, Harris et al., 2002, Gonzalo and Granger, 1995). ILS is Information Leadership share, calculated as in Equation ?? aggregating both IS and CS measures (Yan and Zivot, 2010, Putniňš, 2013). A larger ILS indicates that the series leads price discovery, as indicated by numbers in bold. 


\section{Leadership arbitrage}

Table 6: Gross profit comparison

\begin{tabular}{|c|c|c|c|}
\hline \multicolumn{4}{|c|}{ Closing price } \\
\hline Exchage & Leader & Leadership arbitrage & Buy-and-hold \\
\hline $\begin{array}{l}\text { Mercado Bitcoin } \\
\text { Braziliex }\end{array}$ & $\mathrm{X}$ & BRL $\$ 65,721.32$ & BRL $\$ 165,056.54$ \\
\hline $\begin{array}{l}\text { BitcoinTrade } \\
\text { Mercado Bitcoin }\end{array}$ & $\mathrm{X}$ & BRL\$ 79,050.16 & BRL\$ 168,468.53 \\
\hline $\begin{array}{l}\text { BitcoinTrade } \\
\text { Braziliex }\end{array}$ & $\mathrm{X}$ & BRL $\$ 46,690.27$ & BRL $\$ 165,056.54$ \\
\hline \multicolumn{4}{|c|}{ Opening price } \\
\hline Exchage & Leader & Leadership arbitrage & Buy-and-hold \\
\hline $\begin{array}{l}\text { Mercado Bitcoin } \\
\text { Braziliex }\end{array}$ & $\mathrm{X}$ & BRL\$ 78,821.07 & BRL\$ 164,993.35 \\
\hline $\begin{array}{l}\text { BitcoinTrade } \\
\text { Mercado Bitcoin }\end{array}$ & $\mathrm{X}$ & BRL $\$ 36,717.82$ & BRL\$ $164,648.23$ \\
\hline $\begin{array}{l}\text { BitcoinTrade } \\
\text { Braziliex }\end{array}$ & $\mathrm{X}$ & BRL\$ 37,000.24 & BRL\$ $164,993.35$ \\
\hline
\end{tabular}

We use ILS to selec the leader exchange in our algorithm. 


\section{References}

Aggarwal, Nidhi, "Information share and component share weights: R implementation," Technical Report, Indira Gandhi Institute of Development Research.

Baillie, Richard T., G. Geoffrey Booth, Yiuman Tse, and Tatyana Zabotina, "Price discovery and common factor models," Journal of Financial Markets, jul 2002, 5 (3), 309-321.

Gonzalo, Jesus and Clive Granger, "Estimation of Common Long-Memory Components in Cointegrated Systems," Journal of Business 8 Economic Statistics, jan 1995, 13 (1), 27-35.

Harris, Frederick H. B., Thomas H. McInish, and Robert A. Wood, "Security price adjustment across exchanges: an investigation of common factor components for Dow stocks," Journal of Financial Markets, jul 2002, 5 (3), 277-308.

Hasbrouck, Joel, "One Security, Many Markets: Determining the Contributions to Price Discovery," The Journal of Finance, sep 1995, 50 (4), 1175-1199.

Johansen, Søren, Likelihood-Based Inference in Cointegrated Vector Autoregressive Models, Oxford University Press, dec 1995.

Putniṇš, Tālis J., "What do price discovery metrics really measure?," Journal of Empirical Finance, sep 2013, 23, 68-83.

Yan, Bingcheng and Eric Zivot, "A structural analysis of price discovery measures," Journal of Financial Markets, feb 2010, 13 (1), 1-19. 